\title{
С.В. Разманова
}

\section{ИНТЕГРАЦИЯ ЭКОНОМИЧЕСКИХ СИСТЕМ НА ОСНОВЕ ГАРМОНИЧЕСКОГО РАВНОВЕСИЯ}

\author{
S.V. Razmanova \\ ECONOMIC SYSTEMS INTEGRATION BASED \\ ON HARMONIC BALANCE
}

Понятия и категории, составляющие основу современного мировоззрения о развитии экономических систем, не позволяют предложить объективных законов развития природы и общества. Способность фирм и организаций оказывать воздействие на собственную бизнес-среду сегодня признается ведущими специалистами в области менеджмента. Вместе с тем в доминирующих экономических теориях «мейнстрима» этому не придается большого значения. Цель исследования - обоснование подходов к интеграции компаний в конкурентной среде. Методологической основой исследования избрана современная теория экономических систем, представляющая экономику в виде совокупности взаимодействующих, трансформирующихся и эволюционирующих систем и рассматриваемая как альтернатива неоклассической парадигме с ее делением экономики на макро- и микроэкономику, а также концепция, интегрирующая неоклассический, институциональный и эволюционный подходы. Предложен подход, обосновывающий развитие экономических систем в процессе перехода от индустриального к постиндустриальному обшеству. Его реализация предполагается на основе гармонического равновесия. Аргументировано, что временно устойчивые формы природы, общества и предприятия характеризуются правилом «золотой пропорции» для своих конкурирующих частей. Показано, что взаимная интеграция компании, находящейся в состоянии устойчивого статистического равновесия с неравновесными системами, представленными предприятиями индустриального, постиндустриального и промежуточных форм развития, может осуществляться только в форме поглощения. Соотношение частей экономических систем и их изменений в соответствии с правилом «золотой пропорции» в процессе интеграции компаний может дать ключ к дальнейшему исследованию природы результативности слияний и поглощений.

АНАЛИТИЧЕСКОЕ МЫШЛЕНИЕ; ХОЛИСТИЧЕСКОЕ МЫШЛЕНИЕ; СИСТЕМНАЯ ДИНАМИКА; ТЕОРИЯ ЭКОНОМИЧЕСКИХ СИСТЕМ; ИНТЕГРАЦИЯ; «ЗОЛОТАЯ ПРОПОРЦИЯ»; СТАТИСТИЧЕСКОЕ РАВНОВЕСИЕ.

The concepts and categories currently forming the basis of the contemporary worldview about the development of economic systems do not allow formulating objective laws for nature and society development. The ability of enterprises and organizations to influence their own business environment is now recognized by leading management experts. At the same time, it is not paid enough attention in the dominant mainstream economic theories. The present study is aimed at substantiating the approaches to integration of companies in the competitive environment. The methodology applied in this study is based on a contemporary theory of economic systems representing economics as a complex of interacting, transforming, and evolving systems, regarded as an alternative to the neoclassical paradigm with its division of economics into macro- and microeconomics, as well as the concept integrating neoclassical, institutional, and evolutionary approaches. The paper presents an approach substantiating the development of economic systems in the course of transition from industrial to post-industrial society, which is supposed to be implemented on the basis of harmonic balance. It is finally reasoned that temporarily stable forms of nature, society, and enterprise are characterized by a «golden ratio» rule for their competing parts. It is shown that mutual integration of the company which is in a state of stable statistical equilibrium with unbalanced systems represented by the enterprises of industrial, post-industrial, and intermediate forms of development can be carried out only by merging. According to the «golden ratio» rule, the relationship between the parts of economic systems and their changes during the integration of companies may provide a key to further study of the nature of M\&A effectiveness.

ANALYTICAL THINKING; HOLISTIC THINKING; SYSTEM DYNAMICS; ECONOMIC SYSTEMS THEORY; INTEGRATION; "GOLDEN RATIO”; STATISTICAL EQUILIBRIUM. 
Введение. В основу современного мировоззрения о развитии экономических систем положены понятия и категории, которые имеют научный смысл только в рамках известных динамических теорий или механистического подхода к описанию обратимых во времени явлений природы. Такое мировоззрение не дает способа отличить живую природу от неживой и не может предложить объективные законы развития природы и общества. Сегодня становится очевидным, что в процессе изучения механизма функционирования современной фирмы во внешней среде происходят определенные эволюционные изменения. С одной стороны, понимание природы организации переходит от биологической $\mathrm{K}$ социальной модели, с другой - характер научного познания смещается от аналитического к целостному (холистическому) мышлению.

Сдвиг парадигмы в сторону представлений о фирме как мультиразумной социальной системе не поддается объяснению с позиций механистической или биологической модели. Социальная система (по сути - и наше общество) представляет собой нечто совершенно иное и функционирует по своим собственным законам. В качестве критического параметра в данных системах выступает цель. Согласно Р.Л. Акоффу [1] объект является целеустремленным, если может производить один и тот же результат различными способами в неизменной среде и различные результаты в той же или иной среде. Способность делать выбор - необходимое, но не достаточное условие целеустремленности. Поэтому объект, который может реагировать по-разному, но при этом получает в любой среде один и тот же результат, является самонастраивающимся, а не целеустремленным.

Представителями системной динамики отмечается, что организация, которая по существу является целеустремленной системой, в то же самое время должна рассматриваться как составная часть более крупного целого, т. е. общества, которое, в свою очередь, также относится к целеустремленным системам. Поэтому рассматривая процедуру интеграции организаций в динамике, исследователь наблюдает процесс бесконечной борьбы и столкновения различных интересов. Для эффективного объединения многоуровневых целеустремленных систем необходимо, чтобы исполнение желаний ее участников зависело от выполнения требований более крупной системы и наоборот. Также Р.Л. Акофф и другие исследователи отмечают, что в рамках системного мышления менеджеры компаний должны переосмыслить роль инноваций в конкурентоспособности организаций $[2,3]$.

K ученым, реализующим системную парадигму в своих исследованиях, следует отнести Я. Корнаи, В. Ойкена, К. Поланьи, Ф. фон Хайека, Дж. Форрестера, J. Johannessen, R.J. Allio, Дж. Гараедаги, Ф. Тротвайна, В.-Б. Занга, Э.Э. Петерса. Исторически к ним необходимо отнести и труды К. Маркса, Л. Фон Мизеса, Й. Шумпетера. В отличие от экономистов неоклассического и неоинституционального направлений, сторонники системного подхода ставят своей целью изучение механизмов, определяющих развитие экономической системы на макроуровне. Среди отечественных представителей данного направления выделим Г.Б. Клейнера, В.Л. Макарова, В.Е. Дементьева, А.С. Харитонова, С.Ю. Малкова, С.Г. Кирдину, Л.П. Евстигнееву, Р.Н. Евстигнеева, Д.С. Чернавского, И.Р. Пригожина, Д.Ю. Каталевского, Г.Л. Бекларян, А.С. Акопова.

Сегодня способность фирм и организаций оказывать воздействие на собственную бизнес-среду признается многими экономистами и ведущими менеджерами. Вместе с тем в доминирующих экономических теориях - неоклассической, институциональной - этой способности не придается большого значения.

Методика исследования. Методологической основой исследования избрана современная теория экономических систем, представляющая экономику в виде совокупности взаимодействующих, трансформируюшихся и эволюционирующих систем, и рассматриваемая как альтернатива неоклассической парадигме с ее делением экономики на макро- и микроэкономику, а также концепция, интегрирующая неоклассический, институциональный и эволюционный подходы.

Внимание классической науки сосредоточено на независимых переменных и составляет основу аналитического мышления, которое, по существу, присутствует во всех трех моделях (рис. 1), а именно: в механистической, биологической, социальной. Поэтому целый ряд явлений, в процессе которых возникают эмерджентные свойства, т. е. кото- 
рые появились в результате взаимодействия элементов системы, оставался вне рамок для последующей интерпретации. Вместе с тем исследование поведения систем, опираясь на известный постулат «развитие идет от простого к сложному», показывает, что «по мере усложнения системы проблема взаимной зависимости ее элементов становится все более заметной» [4]. Для понимания того, что элементы системы взаимозависимы, необходимо было сформировать иной образ мышления. В его качестве выступило системное мышление, в его рамках система рассматривается с точки зрения той окружающей среды, частью которой она является.

Еще в начале XX в. Т. Веблен в труде «Почему экономическая наука не является эволюционной дисциплиной?» [5] отмечал, что исследования экономистов-классиков не вполне удовлетворяют требованиям эволюционной науки не потому, что «эти ученые не смогли предложить теорию процесса или причинно-следственных связей, лежащих в основе развития, а потому, что они сформулировали основы своей теории в понятиях, чуждых эволюционному образу мышления». Он подчеркивал, что современный ученый стремится свести решение всех проблем к понятиям «сохранение энергии», «неизменность количества», поскольку это является его последним прибежищем.

В настоящее время в отечественной экономической науке активно развивается новая теория экономических систем. Ее основная парадигма состоит в том, что функционирование экономических субъектов рассматривается через призму процессов создания, взаимодействия, рекомбинации, эволюции и трансформации экономических систем. Отправной точкой в исследовании системного подхода послужил труд Я. Корнаи «Системная парадигма» [6].

\begin{tabular}{|c|c|c|c|}
\hline $\begin{array}{c}\text { СДВИГ } \\
\text { ПАРАДИГМЫ }\end{array}$ & $\begin{array}{c}\text { НЕРАЗУМНАЯ СИСТЕМА } \\
\text { МЕХАНИСТИЧЕСКАЯ } \\
\text { МОДЕЛЬ }\end{array}$ & $\begin{array}{c}\text { СИСТЕМА С ОДНИМ } \\
\text { РАЗУМОМ } \\
\text { БИОЛОГИЧЕСКАЯ МОДЕЛЬ }\end{array}$ & $\begin{array}{c}\text { МУЛЬТИРАЗУМНАЯ } \\
\text { СИСТЕМА } \\
\text { СОЦИАЛЬНАЯ МОДЕЛЬ }\end{array}$ \\
\hline $\begin{array}{c}\text { АНАЛИТИЧЕСКИЙ } \\
\text { ПОДХОД } \\
\\
\text { НЕЗАВИСИМЫЕ } \\
\text { ПЕРЕМЕННЫЕ }\end{array}$ & $\begin{array}{c}\text { НЕРАЗУМНАЯ СИСТЕМА } \\
\text { МЕХАНИСТИЧЕСКАЯ } \\
\text { МОДЕЛЬ } \\
\text { СИстема массового } \\
\text { производства ГенрИ } \\
\text { Форда }\end{array}$ & $\begin{array}{c}\text { РАЗНООБРАЗИЕ И } \\
\text { РОСТ } \\
\text { Дивизиональная } \\
\text { структура } \\
\text { Альфреда Слоуна }\end{array}$ & $\begin{array}{c}\text { ПАРТИСИПАТИВНЫЙ } \\
\text { МЕНЕДЖМЕНТ } \\
\text { Самоорганизующиеся } \\
\text { системы } \\
\text { Социально- } \\
\text { технологическая модель } \\
\text { Тавистокского института }\end{array}$ \\
\hline $\begin{array}{l}\text { СИСТЕМНЫЙ ПОДХОД } \\
\text { ВЗАИМОЗАВИСИМЫЕ } \\
\text { ПЕРЕМЕННЫЕ }\end{array}$ & $\begin{array}{c}\text { ОБЩАЯ } \\
\text { ОптИМИЗАЦИЯ } \\
\text { «Вундеркинды» } \\
\text { компании FORD } \\
\text { Исследование операций }\end{array}$ & $\begin{array}{c}\text { гИБкость и } \\
\text { контРОЛь } \\
\text { Система бережливого } \\
\text { производства Таичи Оно } \\
\text { Кибернетическая модель }\end{array}$ & $\begin{array}{c}\text { РЕКОНСТРУКЦИЯ } \\
\text { Интерактивный } \\
\text { менеджмент Акоффа }\end{array}$ \\
\hline
\end{tabular}

Рис. 1. Направления сдвига парадигмы в представлениях о природе организации и характере научного познания [4] 
В отличие от представителей неоклассической теории и современной институциональной теории, сторонники системного подхода ставят своей целью изучение механизмов, в том числе институциональных, определяющих развитие экономической системы на макроуровне. В России представителем данного направления является Г.Б. Клейнер [7-10]. В рамках его исследований рассмотрение каждого реального экономического объекта осуществляется в системном ракурсе, что предполагает признание его целостности в пространстве и устойчивости во времени. В качестве основных процессов Г.Б. Клейнер выделяет обмен социально-экономической системы с окружающей средой, ее возможности к репродукции и эволюции (на основе механизмов самоорганизации), обеспечение гармонизации внутреннего единства и развития системы с внешними условиями, а также воссоздание систем подобных себе. Тем не менее, «прогнозирование конкретных направлений институциональной эволюции на уровне экономических систем и в этих исследованиях продолжает оставаться пока мало предсказуемым явлением» [11].

Ряд трудов Г.Б. Клейнера посвящен моделированию процессов слияний и поглощений экономических систем [12]. Он отмечает, что понятие «экономическая система» может включать все существующие формы экономический активности субъектов. При этом типология экономических систем рассматривается им с позиции определенных ресурсов. В перечень первичных ресурсов экономических систем Г.Б. Клейнер относит доступное для системы экономическое пространство и располагаемое ею время. В рамках существующих экономических теорий в качестве базисных ресурсов выдвигаются труд, капитал, природный и предпринимательские ресурсы (неоклассическая теория) в дополнение к которым в институциональной теории добавляются ресурсы в виде функционирующих институтов, а в эволюционной экономической теории - рутины, представляющие собой механизмы воспроизводства системы.

Предметом изучения системной экономики являются четыре типа систем - средовые, процессные, проектные и объектные экономические системы, сбалансированное развитие которых представляется наиболее желательным в рамках существующей эко- номической системы. Среди множества возможных видов слияния он выделяет расширяющее и ограничивающее. Под расширяющим слиянием он понимает такую интеграцию экономических систем, при которой возможности организаций расширяются за счет возможностей каждого. По существу, в данном термине мы наблюдаем проявление известной синергетической теории, сформулированной в труде М. Брэдли, А. Десаи и Е. Хан Ким в 1983 г. [13]. «Ограничивающее» слияние предполагает, что возможности новой системы не превосходят возможностей каждого из интегрируемых предприятий. В частности «расширяющее» слияние объектных и процессных экономических систем порождает средовые экономические системы. «Ограничивающее» слияние объектных и процессных экономических систем порождает проектные экономические системы. Основываясь на соответствующем математическом инструментарии, можно сформулировать рекомендации по активизации или ограничению процессов интеграции экономических систем в целях повышения эффективности организации экономики. На наш взгляд, в рамках данной теории остается открытым вопрос, каким образом будут реагировать другие элементы системы в ответ на формирование систем нового типа, образующихся в процессе интеграции, каким образом и за счет чего должна осуществляться балансировка отдельных экономических систем (отраслевых, региональных), на которых отразится интеграция, или экономической системы государства.

Подходы к анализу экономики с позиций самоорганизующейся системы, выдвигаемые зарубежными и отечественными учеными в последние годы, позволяют говорить о становлении «самоорганизационного», или синергетического, подхода в экономических исследованиях. Сторонники самоорганизационного и эволюционного подходов выстраивают во многом близкие концептуальные модели экономики, но при ее изучении концентрируют свое внимание на разных вопросах, и «если эволюционный подход ставит своей задачей изучение свойств экономической динамики, то исследования в русле самоорганизационного подхода направлены не только на анализ эволюционных процессов и фазовых переходов в сложных систе- 
мах, но и на определение законов формирования устойчивых экономических структур в открытых нелинейных системах, на анализ появления "порядка из экономического хаоса”, что сближает его с системным подходом» [11]. Поэтому данный подход применительно к анализу экономических систем можно рассматривать как синтез эволюционного и системного подходов.

Концепция синергизма оказала влияние на управленческое мышление. Исследование интеграционных процессов, проведенное Ф. Тротвайном, свидетельствует о том, что в процессе заключения трансакций именно с помощью синергетической терминологии доказывается их необходимость и последующая целесообразность [14]. Профессор Шведского института перспективных исследований В-Б. Занг показал, что линейность и устойчивость имеют весьма ограниченный характер для экономических эволюционных процессов, а вовсе не универсальный, как это предполагалось в классических экономических теориях. Им исследована возможность использования существующих нелинейных математических моделей синергетического подхода в естественных науках применительно к моделированию поведения экономических систем [15]. В труде Э.Э. Петерса «Хаос и порядок на рынках капитала. Новый аналитический взгляд на циклы, цены и изменчивость рынка» для прогнозирования рыночных котировок были использованы методы фрактального анализа, динамического хаоса и теории самоорганизации И. Пригожина [16].

В процессе рассмотрения специфики управления экономическими системами А.С. Харитонов предлагает использовать аналогию со свойствами живой природы, в связи с чем описывает основные типы действий живого организма [17]. В качестве универсальных типов действий живых организмов он перечисляет работу над средой в целях добычи и потребления ресурсов, адаптацию внутреннего состояния к свойствам окружающей среды посредством установления соответствующих (не менее трех) балансов, воспроизведение себя или подобных себе. Все системы, функционирующие в живой или неживой природе, стремятся повторить себя. Однако неживая природа только воссоздает себя, тогда как живая природа воспроизводит не только себя, но и себе подобных. Ту же самую функцию выполняют и экономические системы.

Многие исследователи отмечают, что рост и развитие - это различные процессы в природе. Рост означает количественное увеличение параметров без существенного качественного изменения системы и является обратимым процессом во времени. Рост и спад экономических показателей всегда имеют предельные пороговые параметры, за которыми наступают кризисные явления. Развитие означает преимущественно нелинейное изменение некоторых параметров самой системы и является необратимым процессом во времени. Развитие связано противоположными изменениями: по одним свойствам система усложняется, а по другим упрощается. Поэтому при анализе и прогнозировании развития целесообразно указывать эти противоположные изменения в организации экономики.

В рамках данного исследования поставлена задача - развить представления о характере интеграции разноуровневых интеллектуальных и материальных составляющих предприятий - экономических систем и его влиянии на создание стоимости объединенной компании, с обоснованием подхода к оценке эффективности объединения предприятий с различными структурами интеллектуального и материального капитала.

Реализация концептуального подхода развития экономических систем в процессе перехода от индустриального к постиндустриальному обществу возможна на основе гармонического равновесия, суть которого состоит в том, что природа в целом находится в равновесии между обобщенными «силами» хаоса и порядка за счет изменения свойств и набора своих частей. Тогда соотношение частей и их изменений описывается правилом золотой пропорции, которое достаточно широко используется в зарубежной экономической науке [18-20]. Однако использование этого более простого и общего принципа устройства природы приводит к тому, что сами объекты природы и экономика в частности являются более сложно организованными системами, чем это обычно принималось в известных теориях.

Пропорции золотого сечения могут быть использованы в процессе интеграции компа- 
ний в условиях совместного воздействия синергии для определения ключевых показателей, оказывающих влияние на рост стоимости объединенной компании, а также на результаты определения коэффициента автономии, а также критерия финансового левериджа, который, в свою очередь, является переменной в структуре показателя эффекта финансового рычага. Анализ производственно-хозяйственной деятельности компаний свидетельствует о том, что гармоничное состояние различных частей и направлений бизнеса, благодаря их структурированию в соответствии с принципами золотого сечения, значительно увеличивает адаптационные возможности интегрированных компаний и способствует их динамичному развитию [21].

Чтобы оценить развитие предприятия, его существование в будущем, выживаемость в конкурентном сотрудничестве с внешней средой предприятия, рассмотрим основные параметры, процессы и направления их развития, которые присущи каждому предприятию, с тем, чтобы понять, как использовать их изменение для сохранения устойчивости конкретного предприятия. Все процессы и явления, происходящие на предприятии и с предприятием, будем рассматривать с энергетической точки зрения, поскольку все события, процессы и явления в природе предприятия движутся энергией, изменяются от воздействия внутренних или внешних энергий. В отличие от механистического подхода [22, 23], в качестве типового логического элемента будет рассматриваться не диада, а триада показателей, равновесие которых принимается в соответствии с правилом 3олотой пропорции. Таким образом, будет осуществлен переход от открытых неравновесных систем к системам, находящимся в покое, гармоническом равновесии за счет изменения своих частей. Заметим, что система находится в механическом равновесии и останется в нем, пока не будет приложена внешняя сила. Статистическое равновесие совсем другого типа. В отличие от механического, в котором конфигурация системы остается статической, система может находиться в статистическом равновесии, даже если ее конфигурация постоянно меняется.

В общем случае на само предприятие, его функционирование и взаимодействие с внеш- ней средой (социально-институциональной, природной), оказывающей влияние на информационные каналы, относительную стабильность существования и выживаемость в ней, оказывают влияние две воздействующие энергии - меры хаоса и порядка. Равенство мер хаоса и мер порядка обеспечивает стабильность предприятия. Для рассмотрения организованной системы предприятия достаточно трех переменных величин.

Три взаимосвязанных изменения меры хаоса позволяют записать их в виде одного уравнения статистической симметрии, при котором происходит самоорганизация системы при правиле золотой пропорции:

$$
\Delta J\left(\sum_{j=1}^{3} m_{j}\right)=\Delta J\left(\sum_{j=1}^{3} n_{j}\right)+\Delta J\left(\sum_{j=1}^{3} r_{j}\right) .
$$

В качестве основных целей предприятия как системы выделим соблюдение следующих параметров:

- равновесие внутри себя между тремя сущностями (параметрами);

- внешнее равновесие с окружающей средой (с другими предприятиями и институтами государства);

- равновесие между этими двумя равновесиями.

Рассмотрим систему трех пространств событий, присущих работе предприятия при эволюционном развитии прогресса, из которых первое пространство событий обозначим формулой $\sum_{j=1}^{3} n_{j}$. В это пространство входят следующие события: число профессий, связанных с ручным трудом; производительность труда; ручной труд.

Второе пространство событий обозначим формулой $\sum_{j=1}^{3} m_{j}$. В это пространство входят следующие события: научно-технический прогресс и потребляемые ресурсы (количественная составляющая); высокие технологии; рост интеллектуального уровня персонала.

Третье пространство событий обозначим формулой $\sum_{j=1}^{3} r_{j}$. В это пространство входят следующие события: принятые нормы и стандарты (количественная составляющая); 
смена мировых трендов; борьба старых устоев (укладов) и новых ценностей.

Для описания характеристик, направлений процессов в этих трех пространствах событий введем новые три переменные величины как формы движения материи - это $i$, $q$, $p$, т. е. три класса переменных величин в наших трех пространствах событий:

Переменная величина $i$ как регулируемый нами в конце рассмотрения признак будет представлять, раскладывать процессысобытия и описывать изменения в трех пространствах событий с точки зрения событий структуры (структурной части) как регулируемого нами в конце признака, переменная величина $q$ - описывать изменения в трех пространствах событий с точки зрения событий координат, переменная величина $p-$ описывать изменения в трех пространствах событий с точки зрения событий импульсов.

Изменение энтропии событий структуры представим как $\Delta J(i)>0$ (рост структурной энтропии). Изменение энтропии событий координат представим как $\Delta J(q)<0$ (уменьшение обычной энтропии, так как пространство координат упорядочивается). Изменение энтропии событий импульсов представим как $\Delta J(p)<0$ (т. е. рост порядка событий по импульсам).

Эти три неравенства можно записать согласно модели в виде одного уравнения статистической симметрии:

$$
\Delta J(i)-\Delta J(q)-\Delta J(p)=0 .
$$

Таким образом, основное уравнение эволюционного развития предприятия как организованной системы можно представить как направленность трех взаимосвязанных процессов, которая при постоянном повышении уровня организации предприятия указывает на условия самоорганизации частей и на определенное соотношение событий структуры, координат и импульсов между собой в равновесии.

Оценим с позиций слияний или поглощений интеграцию предприятия, находящегося в состоянии устойчивого статистического равновесия, с предприятиями четырех типов с разным уровнем развития. Это будут предприятия:

1) индустриального развития,

2) постиндустриального развития,
3) промежуточной (переходной) группы А, у которых материальный капитал больше интеллектуального

4) промежуточной (переходной) группы Б, у которых интеллектуальный капитал больше материального.

Пусть у предприятия индустриального развития совокупный капитал будет тоже распределен по правилу золотой пропорции, поэтому будет находиться в статистическом равновесии и распределяться следующим образом: физический капитал $-50 \%$ от всего капитала предприятия, равного $100 \%$; денежный капитал - 30,9\% от всего капитала предприятия, равного $100 \%$; интеллектуальный капитал - $19,1 \%$ от всего капитала предприятия, равного $100 \%$. Для предприятия постиндустриального развития капитал, распределенный в соответствии с правилом золотой пропорции, находится в статистическом равновесии и структурирован следующим образом: интеллектуальный капитал $50 \%$ от всего капитала предприятия, равного $100 \%$; денежный и физический капитал 30,9 и $19,1 \%$ соответственно. Для предприятия промежуточной (переходной) группы А: денежный капитал - 50 \% от всего капитала предприятия, равного $100 \%$; физический и интеллектуальный капитал - 30,9 и 19,1\% соответственно. Для предприятия промежуточной (переходной) группы Б: денежный капитал - $50 \%$ от всего капитала предприятия, равного $100 \%$; интеллектуальный и физический капитал - 30,9 и 19,1 \% соответственно.

За основу наших дальнейших рассуждений принимаем следующий опытный факт: временно устойчивые формы природы, общества и предприятия характеризуются правилом золотой пропорции для своих конкурирующих частей [21]. В настоящее время имеется много примеров применения технологии золотого сечения для системного и гармоничного управления бизнесом, ценообразованием, финансированием, оплатой труда, экологией природопользования, оценкой эколого-экономического потенциала. Чтобы равенство (2) постоянно выполнялось, постоянно меняющиеся события $i$ должны составлять $50 \%$ от всех событий пространства, события $q-30,9 \%$ от всех событий и события $p-19,1 \%$ от всех рассматриваемых событий пространства. 
Чтобы сопоставить события переменных этих четырех предприятий с событиями $i, q, p$ рассматриваемого предприятия, надо представить их в виде условного соответствия событиям $i, q, p$ по их уровню развития при имеющихся рассматриваемых пропорциях (табл. 1, 2).
Из табл. 2 видно, что следуя логике уравнения (2), для всех четырех предприятий с разным уровнем развития мы получим неравенство как формулу статистической асимметрии:

$$
J(i)-J(q)-J(p)<0,
$$

где $i=33,3 \%$ событий, $q=33,3 \%$ событий, $p=33,3 \%$ событий.

Таблица 1

События, определяющие структуру физического, денежного и интеллектуального капитала (\%) для рассматриваемых видов предприятий

\begin{tabular}{|c|c|c|c|c|c|c|c|c|c|c|c|}
\hline \multicolumn{3}{|c|}{$\begin{array}{c}\text { Предприятия } \\
\text { индустриального развития }\end{array}$} & \multicolumn{3}{|c|}{$\begin{array}{c}\text { Предприятия переходной } \\
\text { группы А }\end{array}$} & \multicolumn{3}{|c|}{$\begin{array}{c}\text { Предприятия переходной } \\
\text { группы Б }\end{array}$} & \multicolumn{3}{|c|}{\begin{tabular}{|c|} 
Предприятия пост- \\
индустриального развития
\end{tabular}} \\
\hline \multicolumn{12}{|c|}{ Физический капитал, представленный следующими событиями } \\
\hline Ручной труд & $50 / 3$ & \multirow[t]{3}{*}{50,0} & Ручной труд & $30,9 / 3$ & \multirow[t]{3}{*}{30,9} & Ручной труд & $19,1 / 3$ & \multirow[t]{3}{*}{19,1} & Ручной труд & $19,1 / 3$ & \multirow[t]{3}{*}{19,1} \\
\hline $\begin{array}{l}\text { Производи- } \\
\text { тельность } \\
\text { ручного труда }\end{array}$ & $50 / 3$ & & \begin{tabular}{|l|} 
Производи- \\
тельность \\
ручного труда
\end{tabular} & $30,9 / 3$ & & \begin{tabular}{|l|} 
Производи- \\
тельность \\
ручного труда
\end{tabular} & $19,1 / 3$ & & \begin{tabular}{|l|} 
Производи- \\
тельность \\
ручного труда
\end{tabular} & $19,1 / 3$ & \\
\hline $\begin{array}{l}\text { Потребляемые } \\
\text { ресурсы } \\
\text { и научно- } \\
\text { технический } \\
\text { прогресс }\end{array}$ & $50 / 3$ & & \begin{tabular}{|l|} 
Потребляемые \\
ресурсы \\
и научно- \\
технический \\
прогресс
\end{tabular} & $30,9 / 3$ & & \begin{tabular}{|l|} 
Потребляемые \\
ресурсы \\
и научно- \\
технический \\
прогресс
\end{tabular} & $19,1 / 3$ & & $\begin{array}{l}\text { Потребляемые } \\
\text { ресурсы } \\
\text { и научно- } \\
\text { технический } \\
\text { прогресс }\end{array}$ & $19,1 / 3$ & \\
\hline \multicolumn{12}{|c|}{ Денежный капитал, представленный следующими событиями } \\
\hline $\begin{array}{l}\text { Высокие } \\
\text { технологии }\end{array}$ & $30,9 / 3$ & \multirow[t]{3}{*}{30,9} & $\begin{array}{l}\text { Высокие } \\
\text { технологии }\end{array}$ & $50 / 3$ & \multirow[t]{3}{*}{50,0} & $\begin{array}{l}\text { Высокие } \\
\text { технологии }\end{array}$ & $50 / 3$ & \multirow[t]{3}{*}{50,0} & $\begin{array}{l}\text { Высокие } \\
\text { технологии }\end{array}$ & $30,9 / 3$ & \multirow[t]{3}{*}{30,9} \\
\hline $\begin{array}{l}\text { Число } \\
\text { профессий, } \\
\text { связанных } \\
\text { с ручным } \\
\text { трудом }\end{array}$ & $30,9 / 3$ & & $\begin{array}{l}\text { Число } \\
\text { профессий, } \\
\text { связанных } \\
\text { с ручным } \\
\text { трудом }\end{array}$ & $50 / 3$ & & \begin{tabular}{|l} 
Число \\
профессий, \\
связанных \\
с ручным \\
трудом
\end{tabular} & $50 / 3$ & & $\begin{array}{l}\text { Число } \\
\text { профессий, } \\
\text { связанных } \\
\text { с ручным } \\
\text { трудом }\end{array}$ & $30,9 / 3$ & \\
\hline $\begin{array}{l}\text { Борьба старых } \\
\text { укладов } \\
\text { и новых } \\
\text { ценностей }\end{array}$ & $30,9 / 3$ & & $\left|\begin{array}{l}\text { Борьба старых } \\
\text { укладов } \\
\text { и новых } \\
\text { ценностей }\end{array}\right|$ & $50 / 3$ & & $\left|\begin{array}{l}\text { Борьба старых } \\
\text { укладов } \\
\text { и новых } \\
\text { ценностей }\end{array}\right|$ & $50 / 3$ & & $\begin{array}{l}\text { Борьба старых } \\
\text { укладов } \\
\text { и новых } \\
\text { ценностей }\end{array}$ & $30,9 / 3$ & \\
\hline \multicolumn{12}{|c|}{ Интеллектуальный капитал, представленный следующими событиями } \\
\hline $\begin{array}{l}\text { Рост интеллек- } \\
\text { туального } \\
\text { уровня } \\
\text { персонала }\end{array}$ & $19,1 / 3$ & \multirow[t]{3}{*}{19,1} & \begin{tabular}{|l|} 
Рост интеллек- \\
туального \\
уровня \\
персонала
\end{tabular} & $19,1 / 3$ & \multirow[t]{3}{*}{19,1} & \begin{tabular}{|l|} 
Рост интеллек- \\
туального \\
уровня \\
персонала
\end{tabular} & $30,9 / 3$ & \multirow[t]{3}{*}{30,9} & $\begin{array}{l}\text { Рост интеллек- } \\
\text { туального } \\
\text { уровня } \\
\text { персонала }\end{array}$ & $50 / 3$ & \multirow[t]{3}{*}{50,0} \\
\hline $\begin{array}{l}\text { Принятые } \\
\text { нормы } \\
\text { и стандарты }\end{array}$ & $19,1 / 3$ & & \begin{tabular}{|l} 
Принятые \\
нормы \\
и стандарты
\end{tabular} & $19,1 / 3$ & & \begin{tabular}{|l|} 
Принятые \\
нормы \\
и стандарты
\end{tabular} & $30,9 / 3$ & & \begin{tabular}{|l|} 
Принятые \\
нормы \\
и стандарты
\end{tabular} & $50 / 3$ & \\
\hline $\begin{array}{l}\text { Смена мировых } \\
\text { трендов }\end{array}$ & $19,1 / 3$ & & \begin{tabular}{|l|} 
Смена мировых \\
трендов
\end{tabular} & $19,1 / 3$ & & \begin{tabular}{|l|} 
Смена мировых \\
трендов
\end{tabular} & $30,9 / 3$ & & \begin{tabular}{|l|} 
Смена мировых \\
трендов
\end{tabular} & $50 / 3$ & \\
\hline
\end{tabular}


Таблица 2

Конкурирующие события структуры, координат и импульсов (\%) для рассматриваемых видов предприятий

\begin{tabular}{|c|c|c|c|c|c|c|c|c|c|c|c|}
\hline \multicolumn{3}{|c|}{\begin{tabular}{|c|} 
Предприятия \\
индустриального развития
\end{tabular}} & \multicolumn{3}{|c|}{$\begin{array}{c}\text { Предприятия переходной } \\
\text { группы A }\end{array}$} & \multicolumn{3}{|c|}{$\begin{array}{c}\text { Предприятия переходной } \\
\text { группы Б }\end{array}$} & \multicolumn{3}{|c|}{$\begin{array}{c}\text { Предприятия пост- } \\
\text { индустриального развития }\end{array}$} \\
\hline \multicolumn{12}{|c|}{ События структуры (карман $i$ ) } \\
\hline $\begin{array}{l}\text { Высокие } \\
\text { технологии }\end{array}$ & $30,9 / 3$ & \multirow{3}{*}{33,3} & $\begin{array}{l}\text { Высокие } \\
\text { технологии }\end{array}$ & $50 / 3$ & \multirow{3}{*}{33,3} & $\begin{array}{l}\text { Высокие } \\
\text { технологии }\end{array}$ & $50 / 3$ & \multirow{3}{*}{33,3} & $\begin{array}{l}\text { Высокие } \\
\text { технологии }\end{array}$ & $30,9 / 3$ & \multirow{3}{*}{33,3} \\
\hline $\begin{array}{l}\text { Рост интел- } \\
\text { лектуального } \\
\text { уровня } \\
\text { персонала }\end{array}$ & $19,1 / 3$ & & \begin{tabular}{|l|} 
Рост интел- \\
лектуального \\
уровня \\
персонала
\end{tabular} & $19,1 / 3$ & & \begin{tabular}{|l} 
Рост интел- \\
лектуального \\
уровня \\
персонала
\end{tabular} & $30,9 / 3$ & & \begin{tabular}{|l} 
Рост интел- \\
лектуального \\
уровня \\
персонала
\end{tabular} & $50 / 3$ & \\
\hline $\begin{array}{l}\text { Потребляемые } \\
\text { ресурсы } \\
\text { и научно- } \\
\text { технический } \\
\text { прогресс }\end{array}$ & $50 / 3$ & & \begin{tabular}{|l|} 
Потребляемые \\
ресурсы \\
и научно- \\
технический \\
прогресс
\end{tabular} & $30,9 / 3$ & & \begin{tabular}{|l|} 
Потребляемые \\
ресурсы \\
и научно- \\
технический \\
прогресс
\end{tabular} & $19,1 / 3$ & & \begin{tabular}{|l|} 
Потребляемые \\
ресурсы \\
и научно- \\
технический \\
прогресс
\end{tabular} & $19,1 / 3$ & \\
\hline \multicolumn{12}{|c|}{ События координат (карман q) } \\
\hline $\begin{array}{l}\text { Принятые } \\
\text { нормы } \\
\text { и стандарты }\end{array}$ & $19,1 / 3$ & \multirow{3}{*}{33,3} & $\begin{array}{l}\text { Принятые } \\
\text { нормы } \\
\text { и стандарты }\end{array}$ & $19,1 / 3$ & \multirow[b]{3}{*}{33,3} & $\begin{array}{l}\text { Принятые } \\
\text { нормы } \\
\text { и стандарты }\end{array}$ & $30,9 / 3$ & \multirow[b]{3}{*}{33,3} & $\begin{array}{l}\text { Принятые } \\
\text { нормы } \\
\text { и стандарты }\end{array}$ & $50 / 3$ & \multirow[b]{3}{*}{33,3} \\
\hline Ручной труд & $50 / 3$ & & Ручной труд & $30,9 / 3$ & & Ручной труд & $19,1 / 3$ & & Ручной труд & $19,1 / 3$ & \\
\hline $\begin{array}{l}\text { Число } \\
\text { профессий, } \\
\text { связанных } \\
\text { с ручным } \\
\text { трудом }\end{array}$ & $30,9 / 3$ & & \begin{tabular}{|l|} 
Число \\
профессий, \\
связанных \\
с ручным тру- \\
дом
\end{tabular} & $50 / 3$ & & \begin{tabular}{|l|} 
Число \\
профессий, \\
связанных \\
с ручным тру- \\
дом
\end{tabular} & $50 / 3$ & & \begin{tabular}{|l|} 
Число \\
профессий, \\
связанных \\
с ручным тру- \\
дом
\end{tabular} & $30,9 / 3$ & \\
\hline \multicolumn{12}{|c|}{ События импульсов (карман $p$ ) } \\
\hline $\begin{array}{l}\text { Смена мировых } \\
\text { трендов }\end{array}$ & $19,1 / 3$ & \multirow{3}{*}{33,3} & $\begin{array}{l}\text { Смена мировых } \\
\text { трендов }\end{array}$ & $19,1 / 3$ & \multirow{3}{*}{33,3} & $\begin{array}{l}\text { Смена мировых } \\
\text { трендов }\end{array}$ & $30,9 / 3$ & \multirow{3}{*}{33,3} & $\begin{array}{l}\text { Смена мировых } \\
\text { трендов }\end{array}$ & $50 / 3$ & \multirow{3}{*}{33,3} \\
\hline $\begin{array}{l}\text { Борьба старых } \\
\text { укладов } \\
\text { и новых } \\
\text { ценностей }\end{array}$ & $30,9 / 3$ & & \begin{tabular}{|l|} 
Борьба старых \\
укладов \\
и новых \\
ценностей
\end{tabular} & $50 / 3$ & & \begin{tabular}{|l|} 
Борьба старых \\
укладов \\
и новых \\
ценностей
\end{tabular} & $50 / 3$ & & \begin{tabular}{|l|} 
Борьба старых \\
укладов \\
и новых \\
ценностей
\end{tabular} & $30,9 / 3$ & \\
\hline \begin{tabular}{l|} 
Производи- \\
тельность \\
ручного труда
\end{tabular} & $50 / 3$ & & \begin{tabular}{|l|} 
Производи- \\
тельность \\
ручного труда
\end{tabular} & $30,9 / 3$ & & \begin{tabular}{|l|} 
Производи- \\
тельность \\
ручного труда \\
\end{tabular} & $19,1 / 3$ & & \begin{tabular}{|l|} 
Производи- \\
тельность \\
ручного труда \\
\end{tabular} & $19,1 / 3$ & \\
\hline \multicolumn{3}{|c|}{$J(i)-J(q)-J(p)<0$} & \multicolumn{3}{|c|}{$J(i)-J(q)-J(p)<0$} & \multicolumn{3}{|c|}{$J(i)-J(q)-J(p)<0$} & \multicolumn{3}{|c|}{$J(i)-J(q)-J(p)<0$} \\
\hline
\end{tabular}

Все события пространства равноправны и равновероятны и формула (3) свидетельствует о том, что существование данных предприятий не является гармоничным, имеет нестабильное развитие, нежизнеспособно для длительного периода времени, так как в конкурирующих процессах структурная компонента (в нашем случае $i$ ) не является большей, а только равна им.
Не случайно формула (3) для рассматриваемых разных уровней предприятия одинакова. Она информирует о том, что эти предприятия одинаково нестабильны, нежизнеспособны для будущего времени, что, в свою очередь, приведет их к завершению жизненного цикла или поглощению другими предприятиями. Именно неравновесность их конкурирующих событий подводит эти предпри- 
ятия к такому финалу. В таком случае равновесно существующее предприятие не может интегрироваться с каждым из рассматриваемых уровней развития предприятий на условиях слияния, поскольку как равноправное объединение слияние вынудит его поддерживать основные принципы нестабильности другого предприятия, что, несомненно, поставит наше успешно работающее предприятие на рельсы неравновесности его конкурирующих событий и приведет к деградации.

Поэтому большинство осуществляемых слияний на самом деле являются лишь присоединениями, поскольку слияние равновесных и гармонических систем само по себе нерядовое, редкое событие. Поэтому успешно функционирующему в состоянии гармонического равновесия предприятию остается только один вариант - это поглощение подобных предприятий с последующим установлением на них своих параметров и пропорций событий. Оно может поглотить другое предприятие, обладающее необходимыми качествами: располагающее нужными ресурсами, имеющее удобную логистику, дополняющее продуктовую линейку и т. д.

Но осуществляя присоединение, предприятие не должно нарушить существующее равновесие, а наоборот, сохранить свою устойчивость и нормальное функционирование в перспективе, укрепив свою систему дополнительными действиями, правами или их делегированием, качеством управления и т. д.

На предприятии, включеном в эволюционный процесс развития, должно присутствовать следующее:

- качественные изменения (высокие технологии, рост интеллектуального уровня персонала, научно-технический прогресс и потребляемые ресурсы, смена мировых трендов и т. д.);

- процесс, необратимый во времени (и это действительно свойство эволюции процессов);

- параметры, изменяющиеся нелинейно (там, где процесс является необратимым, обязательно присутствует нелинейность параметров);

- противоположные изменения - по одним свойствам, процессам система усложняется, по другим упрощается. Например, труднее изобрести или внедрить соответствующее оборудование, механизм, но значительно легче затем нарастить выпуск продукции, собрать ее, упаковать и доставить.

Управление функциями предприятия должно осуществляться по двум конкурирующим секторам: централизованному и периферийному (в том числе и при передаче части своих прав присоединенным предприятиям).

Устойчивое развитие системы будет обеспечиваться за счет пяти равноправных действий:

- работы над средой - работы в целях добычи и потребления ресурсов (энергии, вещества, ресурсов и информации);

- адаптации своего внутреннего состояния к свойствам окружающей среды, нахождения различных (трех) типов балансов с окружающей средой;

- воспроизведения себя или себе подобных предприятий (в том числе ранее присоединенных);

- управления за счет концентрации информации на данном этапе функционирования;

- перестроения функций управления на другой способ функционирования (поскольку зачастую обстоятельства событий подсказывают именно такой выход), т. е. гибкости реагирования.

Схема на рис. 2 является логическим продолжением наших исследований, откорректированных с учетом вышеизложенных позиций.

Поскольку процесс становления и развития предприятия как социально-экономической системы находится под воздействием природных процессов, то прямые линии пересекаются в точке золотого сечения, $\mathrm{AC}: \mathrm{CB}=\mathrm{CB}: \mathrm{AB}=\Phi=0,618$.

Конкурентная энергоемкость компании, равная оси ординат, - лишь частный случай. Она есть функция, представляющая сумму материального (физического и денежного) и интеллектуального капитала в каждой точке оси $J$, т. е. $E=\sum(F, J)=F+J$, и представляет на графике наклонную прямую линию (или горизонтальную, как выражение предельной конкурентной энергоемкости предприятия).

Область ДЕ по всей видимости представляет собой зону полностью автоматизированных высокотехнологичных процессов, осуществляемых на предприятиях, в конструкцию оборудования и техники которых внедрен искусственный интеллект, или разум. 


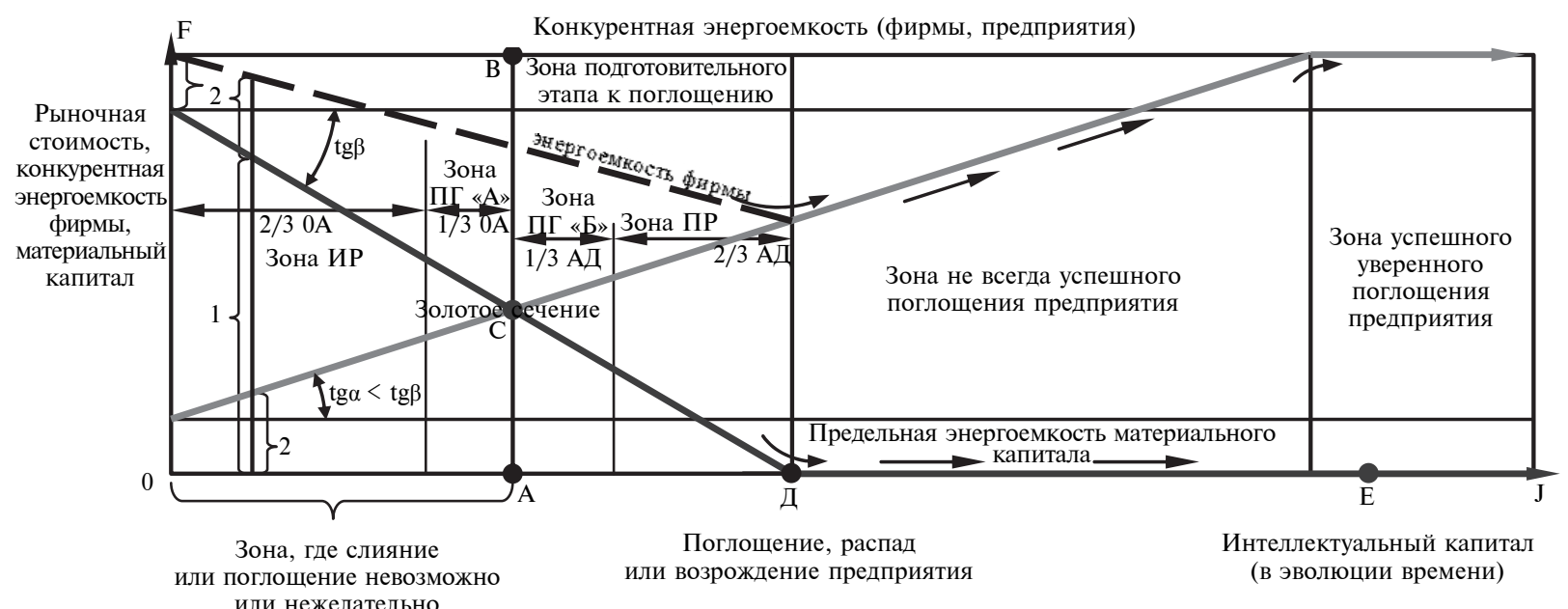

Рис. 2. Области успешной/неуспешной интеграции компаний в зависимости от соотношения интеллектуального и материального (физического и денежного) капитала объединенных компаний

ИР - зона предприятий индустриального типа, ПР - то же постиндустриального типа;

ПГ «А» - зона предприятий переходящего типа с преобладанием материального капитала над интеллектуальным, ПГ «Б» - то же с преобладанием интеллектуального капитала над материальным

Таким образом, взаимная интеграция компании, находящейся в состоянии устойчивого статистического равновесия, с неравновесными системами, представленными предприятиями индустриального, постиндустриального и промежуточных форм развития, может осуществляться только в форме поглощения.

Результаты исследования [17] показали, что «когда внешним воздействием на систему можно пренебречь, то физические, биологические и социально-экономические системы стремятся $\mathrm{K}$ гармоническому равновесию между своими конкурирующими процессами и описываются одним и тем же математическим аппаратом». При этом конкурирующие процессы, происходящие в живой природе, стремятся к такому гармоническому соотношению, при котором структурная компонента является большей.

\section{Результаты исследования}

1. Дано графическое представление механизма интеграции компаний с разной конкурентной энергоемкостью. Выявлено, что взаимная интеграция разноуровневых интеллектуальных и материальных компонентов организованных структур не всегда приводит к созданию стоимости компании.

2. Предложен подход развития экономических систем в процессе перехода от индустриального к постиндустриальному обществу, реализация которого предполагается на основе гармонического равновесия. Обосновано, что временно устойчивые формы природы, общества и предприятия характеризуются правилом золотой пропорции для своих конкурирующих частей.

3. Описаны основные параметры, процессы и направления развития организованных систем в рамках перехода от индустриального к инновационному типу экономики. Обоснованы их последующие изменения для сохранения устойчивости конкретного предприятия.

4. Предложено, что основное уравнение развития предприятия как организованной системы можно представить направленностью трех взаимосвязанных процессов (пространств событий), которая при постоянном повышении уровня организации предприятия указывает на условия самоорганизации частей и на определенное соотношение событий структуры, координат и импульсов между собой в равновесии. Выявлено, что взаимная интеграция компании, находящейся в состоянии устойчивого статистического равновесия с неравновесными системами, может осуществляться только в форме поглощения.

Bыводы. Сегодня со стороны естественных наук гуманитариям предлагается «целый каскад новых понятий», среди которых можно отметить «необратимость времени, информационную природу формирования и функционирования разных структурных 
уровней и систем в целом, открытость сложных систем, квазиравновесие (аттракторы), сложное взаимодействие хаоса и порядка в рамках периодических или качественных непериодических изменений (фазовых переходов, бифуркаций), фрактальное подобие системы в целом и ее разных структурных уровней и компонентов» [24]. Изучение экономики с позиции сложной системы, для которой характерны законы самоорганизации, находится в русле новейших тенденций развития науки в целом.

По мнению С.Г. Кирдиной математический инструментарий, разработанный ранее и успешно применяемый в естественных науках, позволяет исследователям приступить к построению формализованных моделей экономических процессов в рамках новой парадигмы. Однако подчеркивается, что «содержательное переосмысление экономики как сложной самоорганизующейся системы требует формирования новых логических и конструктивных моделей взаимосвязей экономических процессов, расширения поля экономического анализа, что пока не составляет предмет исследований традиционных экономистов» [11].

K методологическим аспектам развития интеграции экономических систем следует отнести: переход характера научного познания мультиразумных систем от аналитического подхода, изучающего независимые переменные, к системному (холистическому) подходу, изучающему взаимозависимые переменные; обоснование математической модели закона развития в современных экономических и естественнонаучных теориях; определение на- правлений развития конкурентных преимуществ организации в условиях становления постиндустриального общества; обоснование основных параметров, процессов и направлений, определяющих результативность интеграционных образований в условиях перехода отечественных предприятий от индустриального к постиндустриальному этапу развития.

Соотношение частей экономических систем и их изменений в соответствии с правилом золотой пропорции в процессе интеграции компаний может дать ключ к дальнейшему исследованию природы результативности слияний и поглощений. При интеграции предприятий с дифференцированной структурой интеллектуального и материального компонентов конкурентной энергоемкости необходимо учитывать, что приобретение поглощающими компаниями с доминирующей долей материального капитала целевых компаний с преобладающим уровнем интеллектуальной составляющей приводит к снижению рыночной стоимости как целевой, так и объединенной компаний.

К основным направлениям дальнейших исследований по рассматриваемой проблематике могут быть отнесены следующие: использование методов математического и имитационного моделирования для оценки эффективности протекания интеграционного процесса и возможных дальнейших вариантов его развития; определение целевых компаний, привлекательных для осуществления интеграции; формирование инвестиционной стратегии фирмы в области интеграции бизнеса в динамично изменяющейся рыночной среде.

\section{СПИСОК ЛИТЕРАТУРЫ}

1. Акофф Р.Л., Эмери Ф.Э. О целеустремленных системах. М.: Эдиториал УРСС, 2008. 272 с.

2. Johannessen J. A systemic approach to innovation: the interactive innovation model // Kybernetes, 2009, vol. 38 , no. $1-2$, pp. $158-176$.

3. Allio R.J., Russell L. Ackoff. Iconoclastic management authority, advocates a «systemic» approach to innovation // Strategy \& Leadership, 2003, vol. 31, no. 3, pp. 19-26.

4. Gharajedaghi J. Systems Thinking: Managing Chaos \& Complexity: A Platform for Designing Business Architecture. Elsevier, 2012. 376 p.

5. Веблен Т. Почему экономическая наука не является эволюционной дисциплиной? / Истоки.
Из опыта изучения экономики как структуры и процесса. М.: Изд. дом ГУ ВШЭ, 2006. С. 10-32.

6. Корнаи Я. Системная парадигма // Вопросы экономики. 2002. № 4. С. 141-149.

7. Клейнер Г.Б. Эволюция институциональных систем. М.: Наука, 2004. 240 с.

8. Клейнер Г.Б. Системная парадигма и экономическая политика // Общественные науки и современность. 2007. № 2. С. 141-149.

9. Клейнер Г.Б. Системная парадигма и экономическая политика // Общественные науки и современность. 2007. № 3. С. 99-114.

10. Kleiner G.B. The development of the economic systems theory and its applications on corporate 
governance and strategic management. Preprint \#WP/99/2010, 2010. 43 p.

11. Кирдина С.Г. Институциональные изменения и принцип Кюри // Экономическая наука в современной России. 2011. № 1. С. 19-38.

12. Клейнер Г.Б. Моделирование слияний и поглощений экономических систем // Стратегическое планирование и развитие предприятий матер. Тринадцатого всерос. симпозиума. 2012. Т. 1. C. $82-86$.

13. Bradley M., Desai A., Kim E.H. The rationale behind interfirm tender offers // Journal of Financial Economics, 1983, vol. 11, pp. 183-206.

14. Trautwein F. Merger Motives and Megrers Prescriptions // Strategic Managements Journal, 1990, vol. 11, no. 4, pp. 283-295.

15. Занг В.-Б. Синергетическая экономика. Время и перемены в синергетической экономической теории. М.: Мир, 1999. 335 с.

16. Петерс Э.Э. Хаос и порядок на рынках капитала. Новый аналитический взгляд на циклы цены и изменчивость рынка. М.: Мир, 2000. 333 с.

17. Харитонов А.С. Минимальное число параметров, характеризующих социально-экономиче- ское развитие регионов // Аудит и финансовый анализ. 2002. № 1. С. 193.

18. Алле М. Условия эффективности в экономике. М.: Наука для общества, 1998. 304 с.

19. Эрлих А.А. Технологический анализ товарных и финансовых рынков. М.: Инфра-М, 1996. 176 с.

20. Пректер Р., Фрост А. Волновой принцип Эллиотта. Ключ к пониманию рынка. М.: Альпина Паблишер, 2012. 270 с.

21. Ястребинский М.А., Гусева Н.М. Синергия слияния (M\&A) горных компаний с применением технологии золотого сечения // Научный вестник МГГУ. 2013. № 12(45). С. 289-305.

22. Разманова С.В. Структура капитала интегрируемых фирм и результативность процессов слияний и поглощений // Стратегическое планирование и развитие предприятий : матер. четырнадцатого всерос. симп. 2013. Т. 1. С. 121-123.

23. Razmanova S.V. Essay on corporate competitive energy capacity // International Journal of Advanced Studies, 2013, vol. 3, no. 1, pp. 55-67.

24. Евстигнеева Л.П., Евстигнеев Р.Н. Методологические основы экономической синергетики : [научный доклад]. М.: ИЭ РАН, 2007. 64 с.

\section{REFERENCES}

1. Akoff R.L., Emeri F.E. O tseleustremlennykh sistemakh. M.: Editorial URSS, 2008. 272 s. (rus)

2. Johannessen J. A systemic approach to innovation: the interactive innovation model. Kybernetes, 2009, vol. 38, no. 1-2, rr. 158-176.

3. Allio R.J., Russell L. Ackoff. Iconoclastic management authority, advocates a «systemic» approach to innovation. Strategy \& Leadership, 2003, vol. 31, no. 3 , pp. $19-26$.

4. Gharajedaghi J. Systems Thinking: Managing Chaos \& Complexity: A Platform for Designing Business Architecture. Elsevier, 2012. 376 p.

5. Veblen T. Pochemu ekonomicheskaia nauka ne iavliaetsia evoliutsionnoi distsiplinoi? Istoki. Iz opyta izucheniia ekonomiki kak struktury i protsessa. M.: Izd. dom GU VShE, 2006. S. 10-32. (rus)

6. Kornai Ia. Sistemnaia paradigm. Voprosy ekonomiki. 2002. № 4. S. 141-149. (rus)

7. Kleiner G.B. Evoliutsiia institutsional'nykh sistem. M.: Nauka, 2004. 240 s. (rus)

8. Kleiner G.B. Sistemnaia paradigma i ekonomicheskaia politika. Obshchestvennye nauki i sovremennost'. 2007. № 2. S. 141-149. (rus)

9. Kleiner G.B. Sistemnaia paradigma i ekonomicheskaia politika. Obshchestvennye nauki i sovremennost'. 2007. № 3. S. 99-114. (rus)

10. Kleiner G.B. The development of the economic systems theory and its applications on corporate governance and strategic management. Preprint \#WP/99/2010, 2010. 43 p.
11. Kirdina S.G. Institutsional'nye izmeneniia i printsip Kiuri. Ekonomicheskaia nauka v sovremennoi Rossii. 2011. № 1. S. 19-38. (rus)

12. Kleiner G.B. Modelirovanie sliianii i pogloshchenii ekonomicheskikh system. Strategicheskoe planirovanie $i$ razvitie predpriiatii : mater. Trinadtsatogo vseros. simpoziuma. 2012. T. 1. S. 82-86. (rus)

13. Bradley M., Desai A., Kim E.H. The rationale behind interfirm tender offers. Journal of Financial Economics, 1983, vol. 11, pp. 183-206.

14. Trautwein F. Merger Motives and Megrers Prescriptions. Strategic Managements Journal, 1990, vol. 11, no. 4, rp. 283-295.

15. Zang V.-B. Sinergeticheskaia ekonomika. Vremia i peremeny $\mathrm{v}$ sinergeticheskoi ekonomicheskoi teorii. M.: Mir, 1999. 335 s. (rus)

16. Peters E.E. Khaos i poriadok na rynkakh kapitala. Novyi analiticheskii vzgliad na tsikly tseny i izmenchivost' rynka. M.: Mir, 2000. 333 s. (rus)

17. Kharitonov A.S. Minimal'noe chislo parametrov, kharakterizuiushchikh sotsial'no-ekonomicheskoe razvitie regionov. Audit i finansovyi analiz. 2002. № 1. S. 193. (rus)

18. Alle M. Usloviia effektivnosti v ekonomike. M.: Nauka dlia obshchestva, 1998. 304 s. (rus)

19. Erlikh A.A. Tekhnologicheskii analiz tovarnykh i finansovykh rynkov. M.: Infra-M, 1996. 176 s. (rus)

20. Prekter R., Frost A. Volnovoi printsip Elliotta. Kliuch $\mathrm{k}$ ponimaniiu rynka. M.: Al'pina Pablisher, 2012. $270 \mathrm{~s}$. 
21. Iastrebinskii M.A., Guseva N.M. Sinergiia sliianiia (M\&A) gornykh kompanii s primeneniem tekhnologii zolotogo secheniia. Nauchnyi vestnik $M G G U$. 2013. № 12(45). S. 289-305. (rus)

22. Razmanova S.V. Struktura kapitala integriruemykh firm i rezul'tativnost' protsessov sliianii i pogloshchenii. Strategicheskoe planirovanie i razvitie predpriiatii : mater. chetyrnadtsatogo vseros. simp. 2013. T. 1. S. 121-123. (rus)

23. Razmanova S.V. Essay on corporate competitive energy capacity. International Journal of Advanced Studies, 2013, vol. 3, no. 1, pp. 55-67.

24. Evstigneeva L.P., Evstigneev R.N. Metodologicheskie osnovy ekonomicheskoi sinergetiki : nauchnyi doklad. M.: IE RAN, 2007. 64 s. (rus)

РАЗМАНОВА Светлана Валерьевна - начальник лаборатории «Экономическая эффективность проектов разработки» филиала ООО «Газпром ВНИИГАЗ» в г. Ухта, кандидат экономических наук.

169300, ул. Севастопольская, д. 1a, г. Ухта, Республика Коми, Россия. E-mail: s.razmanova@sng.vniigaz.gazprom.ru

RAZMANOVA Svetlana V. - Gazprom VNIIGAZ, Ukhta Branch Office.

169300. Sevastopolskaya str. 1a. Ukhta. Komi Pepublic. Russia. E-mail: s.razmanova@sng.vniigaz.gazprom.ru 